\title{
Perbedaan Kadar Leukosit pada Ibu Ketuban Pecah Dini dan Partus Lama
}

\author{
Jumriani1) Nasrum Massi' ${ }^{2)}$ Werna Nontji ${ }^{3)}$ \\ ${ }^{1}$ Bagian Kebidanan, Sekolah Pasca Sarjana, Universitas Hasanuddin, Makassar 90245 \\ ${ }^{2}$ Bagian Mikrobiologi, Fakultas Kedokteran, Universitas Hasanuddin, Makassar 90245 \\ ${ }^{3}$ Bagian keperawatan, Rumah Sakit Pendidikan Unhas, Makassar 90245
}

(Email: jumriani26@gmail.com)

\begin{abstract}
Abstrak. Peningkatan kadar leukosit dalam tubuh diketahui sebagai penyebab terjadinya infeksi pada ibu ketuban pecah dini (KPD) dan partus lama. Penelitian ini bertujuan untuk mengetahui perbedaan kadar leukosit pada ibu ketuban pecah dini (KPD) dan partus lama. Desain penelitian yang digunakan adalah Cross Sectional Study dengan jumlah sampel sebanyak 120 responden yang terdiri dari dua kelompok yaitu 60 responden dengan kasus ketuban pecah dini dan 60 responden dengan partus lama. Analisis data menggunakan uji Mann Whitney untuk mengetahui perbedaan kadar leukosit pada ibu ketuban pecah dini dan partus lama. hasil didapatkan nilai $p$ value 0,022 $(<\alpha=0,05)$ hal ini menujukkan bahwa ada perbedaan peningkatan kadar leukosit pada ibu ketuban pecah dini (KPD) dan partus lama, dimana rerata kadar leukosit kelompok KPD jauh lebih besar dibandingkan dengan kelompok partus lama dengan nilai $14.280 \mathrm{~mm}^{3}$ dan $12.003 \mathrm{~mm}^{3}$.
\end{abstract}

Kata Kunci : kadar Leukosit, Ketuban pecah dini, Partus lama

\section{Differences in Leukocyte Levels Premature rupture of membranes and prolonged labor at Al-Fatah Hospital, Ambon}

\begin{abstract}
The leucocyte content increased in the body is recognized as the cause on the infection incident on the women with the premature rupture membranes and long partum. The research aimed to investigate the leucocyte content difference on the women the premature rupture membranes and long partum. The research design used was a cross sectional study with a total sample of 120 respondents consisting of two groups, namely 60 respondents with cases of premature rupture of membranes and 60 respondents with prolonged labor. Data analysis using Mann Whitney's test indicates the $p$ value of $0.022(<\alpha=0.05)$. This indicates that there is the difference of the leukocyte content increase on the women with the premature rupture membrane and long partum, In which the mean of the leucocyte content of PRM group is much bigger than the long partum group with the values of $14,280 \mathrm{~mm}^{3}$ and $12,003 \mathrm{~mm}^{3}$.
\end{abstract}

Keywords : Leucocyte content, premature rupture membrane, long Partum

\section{Pendahuluan}

Ketuban pecah dini (KPD) adalah keadaan pecahnya selaput ketuban sebelum persalinan atau dimulainya tanda inpartu buku saku pelayanan kesehatan ibu difasiltas kesehatan dasar dan rujukan (2013). Pada kasus Ketuban Pecah Dini (KPD), memungkinkan kuman dapat masuk ke dalam tubuh sehingga dapat menimbulkan infeksi, masuknya kuman/infeksi menyebabkan Peningkatan jumlah leukosit (Leukositosis), Kasus dalamm penelitian ini selain ketuban pecah dini (KPD) yang mempengaruhi infeksi juga partus lama. Partus lama adalah waktu persalinan yang memanjang karena 
kemajuan persalinan yang terhambat (Kementrian Kesehatan RI, 2013a). Salah satu faktor yang mempengaruhi lamanya persalinan adalah infeksi, infeksi intrapartum (Prawirohardjo, 2009).

Angka kematian ibu ditahun 2010 lebih dari 300-400/100.000 kelahiran hidup, yang disebabkan oleh perdarahan $28 \%$, KPD $20 \%$, partus lama $18 \%$, abortus $13 \%$, eklamsia $12 \%$ dan penyebab lainnya $2 \%$, Sedangkan di Indonesia angka kematian ibu (AKI) mencapai 359 per 100.000 kelahiran hidup dan angka kematian bayi (AKB) mencapai 32 per 1.000 kelahiran hidup. Penyebab kematian ibu yaitu perdarahan $(30,3 \%)$, hipertensi $(27,1 \%)$, infeksi $(7,2 \%)$, partus lama $(1,8 \%)$, abortus $(1,6 \%)$ dan lain-lain $(40,8 \%)$ Survey Demografi Dan Kesehatan Indonesia (World Health Organizaion, 2010).

Studi penelitian tentang Ketuban Pecah Dini (KPD) Dan Kadar Leukosit Pada Ibu Bersalin menunjukkan bahwa dari 81 orang $(85,3 \%)$ yang PROM terdapat 68 orang $(71,5 \%)$ mengalami leukositosis, sedangkan 12 orang (12,6\%) memiliki kadar leukosit normal dengan kadar leukosit $(4,000-11,00) \mathrm{mm}$, dan 1 orang memiliki kadar leukosit meningkat dengan kadar $>11.00 \mathrm{~mm}$. Hasil penelitian ini menunjukkan bahwa ada hubungan antara ketuban pecah dini (KPD) dengan kadar leukosit (Widyana, 2016).

Berdasarkan penelitian Sudarmi \& Aisyah (2015), Menunjukkan bahwa dari 82 ibu yang partus lama terdapat 11 ibu yang mengalami infeksi intrapartum dan 71 ibu yang tidak mengalami infeksi, Hasil penelitian ini menunjukkan bahwa ada hubungan antara infeksi.

Sesuai dengan data - data tersebut sehingga memerlukan suatu penelitian untuk mendeteksi penanganan ketuban pecah dini (KPD) dan partus lama yang menyebabkan infeksi, Sehingga peneliti tertarik mengangkat permasalahan tersebut untuk dilakukan penelitian.

Tujuan umum Penelitian ini adalah untuk mengetahui perbedaan kadar leukosit pada ibu ketuban pecah dini (KPD) dan Partus lama.

\section{Metode Penelitian \\ Lokasi Penelitian}

Penelitian ini dilaksanakan di rumah sakit umum Al-Fatah Ambon. Waktu penelitian dilaksanakan pada tanggal 1 Februari sampai 1 April 2018.

\section{Populasi dan Sampel}

Populasi dalam penelitian ini adalah semua ibu bersalin yang dirawat di rumah sakit Al- Fatah Ambon berjumlah 75 ibu ketuban pecah dini dan 75 ibu partus lama. Jumlah sampel dengan menggunakan tabel Issac dan Michael, Sampel dalam penelitian sebanyak 60 orang yang telah memenuhi kriteria inklusi yaitu ibu yang mengalam ketuban pecah dini dan partus lama di rumah sakit Al-Fatah Ambon, responden yang bersedia menjadi sampel dengan no 97/H4.8.4.5.31/PP36-KOMETIK/ 2018.

\section{Metode Pengumpulan Data}

Data primer diperoleh langsung dari responden yang sesuai dengan kriteria inklusi dan mengisi lembar informed consent. Dalam penelitian ini terdapat dua kelompok yaitu kelompok I ketuban pecah dini sebanyak 60 responden, kelompok II partus lama sebanyak 60 responden. Data sekunder diperoleh pengambilan data awal di rumah sakit umum Al-Fatah Ambon.

\section{Analisis Data}

Pengolahan data secara komputerisasi dengan menggunakan program SPSS versi 20,0. Analisa data dilakukan secara sistematik. Metode Statistik untuk analisa data yang digunakan dalam penelitian ini yaitu analisis univariat disajikan dalam bentuk 
tabel distribusi frekuensi disertai dengan penjelasan tabel, analisis bivariat dilakukan untuk menilai perbedaan kadar leukosit antara kelompok I ketuban pecah dini dan kelompok II partus lama, dianalisis dengan uji chi squae dan uji mann whitney.

\section{Hasil}

Tabel 1 menunjukkan bahwa berdasarkan umur ibu, paritas, umur kehamilan, IMT dan Hemoglobin tidak ada perbedaan yang bermakna antara kelompok ketuban pecah dini dan partus lama. Sehingga hal ini menunjukkan bahwa sampel penelitian ini besifat homogen.

Tabel 1. Distribusi Frekuensi Karakteristik Responden di RSU AlFatah Ambon

\begin{tabular}{|c|c|c|c|c|c|}
\hline \multirow[t]{2}{*}{ Variabel } & \multicolumn{2}{|c|}{ KPD } & \multicolumn{2}{|c|}{ Partus Lama } & \multirow{2}{*}{$\begin{array}{c}P \\
\text { value }\end{array}$} \\
\hline & n & $(\%)$ & $\mathrm{n}$ & $(\%)$ & \\
\hline \multicolumn{6}{|l|}{ Umur } \\
\hline $\begin{array}{l}\text { Risiko } \\
\text { rendah }\end{array}$ & 48 & 51,6 & 45 & 48,4 & \multirow[t]{2}{*}{0,662} \\
\hline $\begin{array}{l}\text { Risiko } \\
\text { tinggi }\end{array}$ & 12 & 44,4 & 15 & 55,6 & \\
\hline \multicolumn{6}{|l|}{ Paritas } \\
\hline Primi & 9 & 47,4 & 10 & 52,6 & \multirow[t]{2}{*}{1} \\
\hline Multi & 51 & 50,5 & 50 & 49,5 & \\
\hline \multicolumn{6}{|l|}{ Umur } \\
\hline Kehamilan & & & & & \\
\hline Aterm & 53 & 47,7 & 58 & 52,3 & \multirow[t]{2}{*}{$0,166^{*}$} \\
\hline Preterm & 7 & 77,8 & 2 & 22,2 & \\
\hline \multicolumn{6}{|l|}{ IMT } \\
\hline Normal & 48 & 50,5 & 47 & 49,5 & \multirow[t]{2}{*}{1} \\
\hline Tidak & 12 & 48 & 13 & 52 & \\
\hline \multicolumn{6}{|l|}{ Hemoglobin } \\
\hline Normal & 39 & 48,8 & 41 & 51,2 & \multirow[t]{2}{*}{0,846} \\
\hline Anemia & 21 & 52,5 & 19 & 47,5 & \\
\hline
\end{tabular}

Tabel 2 Dari hasil uji Chi square Menunjukkan bahwa dari 120 responden, mayoritas responden dengan katagori paritas Multi pada kelompok ibu ketuban pecah dini dengan kadar leukosit normal sebanyak 13 orang $(21,7 \%)$ dan kadar leukosit meningkat sebanyak 38 orang $(63,3 \%)$, Pada kelompok partus lama mayoritas responden dengan katogori paritas Multi dengan kadar leukosit normal sebanyak 24 orang $(40 \%)$ dan meningkat sebanyak 26 orang $(43,3 \%)$.

Tabel 2. Tabel Distribusi Kadar Leukosit Pada Ibu Ketuban Pecah Dini Dan Partus Lama

\begin{tabular}{|c|c|c|c|c|c|}
\hline \multirow{3}{*}{ Leukosit } & \multicolumn{4}{|c|}{ KPD } & \multirow{3}{*}{$\begin{array}{c}p \\
\text { Value }\end{array}$} \\
\hline & \multicolumn{2}{|c|}{ Primi } & \multicolumn{2}{|c|}{ Multi } & \\
\hline & $\mathbf{n}$ & $\%$ & $\mathbf{n}$ & $\%$ & \\
\hline Normal & 2 & 3,3 & 13 & 21,7 & \\
\hline Meningkat & 7 & 11,7 & 38 & 63,3 & $0,427^{*}$ \\
\hline \multirow{3}{*}{ Leukosit } & \multicolumn{4}{|c|}{ Partus lama } & \\
\hline & \multicolumn{2}{|c|}{ Primi } & \multicolumn{2}{|c|}{ Multi } & $\boldsymbol{p}$ \\
\hline & $\mathbf{n}$ & $\%$ & $\mathbf{n}$ & $\%$ & \\
\hline Normal & 4 & 6,7 & 24 & 40 & \\
\hline Meningkat & 6 & 10 & 26 & 43,3 & $0,737^{*}$ \\
\hline
\end{tabular}

Tabel 3 Menunjukkan bahwa kadar leukosit secara statistik memiliki hubungan yang bermakna antara kelompok ibu ketuban pecah dini (KPD) dan partus lama. ibu yang mengalami KPD memiliki kecenderungan mengalami peningkatan kadar leukosit sebesar 2,6 kali dibandingkan dengan ibu hamil yang tidak mengalami ketuban pecah dini.

Tabel 3. Hubungan nilai kadar leukosit pada ibu ketuban pecah dini dan partus lama

\begin{tabular}{ccccccc}
\hline \multirow{2}{*}{ Kelompok } & \multicolumn{2}{c}{ KPD } & \multicolumn{2}{c}{$\begin{array}{c}\text { Partus } \\
\text { Lama }\end{array}$} & $\begin{array}{c}\text { P } \\
\text { Value }\end{array}$ & $\begin{array}{c}\text { OR } \\
(\mathbf{9 5 \%} \text { CI) }\end{array}$ \\
\cline { 2 - 5 } & $\mathbf{n}$ & $\mathbf{( \% )}$ & $\mathbf{n}$ & $\mathbf{( \% )}$ & & \\
\hline Normal & 15 & 25 & 28 & 75 & & 2,625 \\
Meningkat & 45 & 53,5 & 32 & 46,7 & 0,022 & $(1,211-5,691)$ \\
\hline Chi Square & & & & & &
\end{tabular}

Tabel 4 menunjukkan bahwa ada perbedaan kadar leukosit pada ibu ketuban pecah dini dan partus lama dimana nilai $p$ value 0,022 lebih kecil dari 0,05. Rerata leukosit kelompok KPD jauh lebih besar dibandingkan dengan kelompok partus lama dengan nilai 14.280 dan 12.003 .

Tabel 4. Hasil Analisis rerata kadar leukosit pada ibu ketuban pecah dini dan partus lama 


\begin{tabular}{ccc}
\hline Kelompok & $\begin{array}{c}\text { Rerata Kadar } \\
\text { Leukosit (S.D) }\end{array}$ & P Value \\
\hline KPD $(\mathrm{n}=60)$ & $14.280(5,4)$ & 0,022 \\
Partus Lama $(\mathrm{n}=60)$ & $12.003(3,7)$ & \\
\hline
\end{tabular}

Mann Whitney

\section{Pembahasan}

Hasil penelitian pada kasus Ketuban pecah dini (KPD) dan partus lama menggunakan uji statistic Mann Whitney didapatkan nilai $p$ value 0,022 $(<0,05)$, menunjukkan bahwa ada hubungan peningkatan kadar leukosit pada ibu ketuban pecah dini dan partus lama.

Ketuban pecah dini adalah pecahnya selaput ketuban secara spontan tanpa disertai tanda-tanda persalinan. Insidenya sekitar $10,7 \%$ dari seluruh persalinan, dimana $94 \%$ diantaranya terjadi pada kehamilan cukup bulan (Mercer et al., 2015). Faktor risiko terjadinya KPD salah satunya adalah infeksi, status nutrisi, paritas dan lainlain. Faktor yang paling signifikan adalah adanya infeksi bakteri dari traktus genetalis. Bakteri yang paling sering ditemukan adalah Escherichia collie, klebsiela spesies dan grup Beta streptokokus. Bakteri-bakteri ini memproduksi fosfolipase A2, kolagenase dan protease lainya yang menyebabkan perubahan $\mathrm{pH}$. Beberapa penelitian juga menunjukan adanya perubahan elastisitas sekunder dan jaringan kolagen yang dapat menyebabkan selaput ketuban pecah (Fernando, 2013).

Leukosit merupakan sel yang berperan dalam pertahanan tubuh. Hitung jumlah leukosit adalah pemeriksaan untuk menentukan jumlah leukosit yang terdapat dalam $1 \mathrm{~mL}$ darah untuk membantu dalam menentukkan adanya peningkatan jumlah leukosit (leukositosis) atau penurunan jumlah leukosit (leukopenia) yang menjadi suatu tanda adanya infeksi (Nugraha, 2015). Studi di Malang mengatakan bahwa ada hubungan antara ketuban pecah dini dengan kadar leukosit dengan nilai $\mathrm{p}=$ 0,004 >0,05 (Widyana, 2016). Infeksi bakteri dan respon inflamasi juga menginduksi produksi prostaglandin oleh selaput janin yang diduga meningkatkan risiko KPD. Demikian pula dengan hasil temuan di NTB menyatakan bahwa ada hubungan antara infeksi dengan ketuban pecah dini dengan nilai $P$ value $=0,013$ (Sudarmi \& Aisyah, 2015). Hal senada juga dengan penelitian Lewis \& Parry (2013), dimana ditemukan adanya hubungan yang kuat adanya infeksi dengan kejadian KPD.

Sel darah putih dalam tubuh terdapat lima jenis yaitu neutrofil, eosinofil, basofill, monosit, dan limfosit, Neutrofil merupakan jenis sel yang paling banyak dalam tubuh mencapai (50-70\%). Neutrofil berperan penting dalam garis depan pertahanan tubuh terhadap invasi zat asing. Neutrofil bersifat fagosit dan dapat masuk kedalam jaringan yang terinfeksi. Satu sel neutrofil dapat memfagosit 5-20 bakteri dengan masa hidup sekitar 6-10 jam dan leukosit jenis ini yang akan meningkat ketika terjadi infeksi (Nugraha, 2015). Penelitian dilakukan terhadap ibu hamil cukup bulan dengan riwayat infeksi vagina, ditemukan $K P D$ pada 30,6\% subyek (Blok et al., 2011).

Kasus dalam penelitian ini selain ketuban pecah dini (KPD) yang mempengaruhi infeksi juga partus lama. hasil analisis statistik menggunakan uji mann whitney didapatkan rerata kadar leukosit pada ibu partus lama sebesar $12.003 \mathrm{~mm}^{3}$ dengan nilai $p$ value 0,022 $(<0,05)$ menunjukkan ada hubungan peningkatan kadar leukosit dengan partus lama. Partus lama adalah waktu persalinan yang memanjang karena kemajuan persalinan yang terhambat (Kementrian Kesehatan RI, 2013b). Salah satu factor yang mempengaruhi lamanya persalinan adalah infeksi, 
infeksi intrapartum (Prawirohardjo, 2009).

Sejalan dengan Penelitian Alim \& Safitri (2016), ada pengaruh partus lama dengan infeksi sebesar 19\%, Hasil penelitian ini menyatakan bahwa ibu yang mengalami partus lama berhubungan dengan peningkatan kadar leukosit. senada dengan Penelitian Sudarmi \& Aisyah (2015), menyatakan bahwa ada hubungan antara infeksi dengan lama persalinan dengan nilai $p$ value $=0,013(<0,05)$.

Berdasarkan hasil penelitian didapatkan rerata kadar leukosit pada ibu yang mengalami ketuban pecah dini adalah $14.280 / \mathrm{mm}^{3}$ sedangkan pada kelompok partus lama yaitu $12.003 / \mathrm{mm}^{3}$. Pada penelitian ini didapatkan perbedaan yang bermakna dengan nilai $p=0,022<0,005$. Dimana rerata kadar leukosit pada ibu ketuban pecah dini lebih tinggi dari pada ibu yang partus lama, Artinya Ibu yang mengalami ketuban pecah dini memiliki kecenderungan mengalami peningkatan kadar leukosit sebesar 2,6 kali dibandingkan dengan ibu partus lama.

Ibu dengan kasus Ketuban pecah dini lebih berisiko mengalami Peningkatan kadar leukosit dari pada partus lama karena KPD menyebabkan hubungan langsung antara dunia luar dan ruangan dalam Rahim sehingga mengakibatkan terjadinya infeksi, infeksi yang terjadi disebabkan oleh masuknya mikroorganisme ke dalam cavum uteri sehingga menyebabkan bakteri jahat masuk ke dalam vagina dan meningkatkan $\mathrm{PH}$ pada Vagina, hal ini menimbulkan reaksi peradangan, reaksi peradangan ini menyebabkan leukosit yang biasanya tinggal di dalam kelenjar limfe, beredar ke dalam darah menyebabkan leukosit meningkat (McPhee et al., 2012), sedangkan pada pada kasus partus lama peningkatan kadar leukosit disebabkan oleh hygiene yang kurang baik dan komplikasi VT yaitu VT yang berulang - ulang.

\section{Simpulan}

Pada ibu ketuban pecah dini lebih tinggi dibandingkan dengan rerata kadar leukosit pada ibu partus lama, ibu hamil dengan ketuban pecah dini lebih beresiko terjadinya leukositosis sebesar 2,6 kali dibandingkan ibu partus lama, perlu dipertimbangkan untuk memerika kadar leukosit sebelum merencanakan kehamilan untuk mencegah terjadinya ketuban pecah dini dan partus lama.

\section{Daftar Pustaka}

Alim \& Safitri. (2016). Faktor - faktor yang berhubungan dengan lama persalinan. Jurnal Hesti Wira Sakti, $4(1), 101-109$.

Blok R. et al. (2011). The role of lower genital tract infection in PROM. Journal Ginekol, 68(10), 449-458.

Fernando A. (2013). Premature rupture of the membrane. Jounal Practical Guideline to High Risk Pregnancy, 3, 100-113.

Kementrian Kesehatan RI. (2013a). Buku saku pelayanan kesehatan Ibu di fasilitas kesehatan dasar dan rujukan (Kementrian Kesehatan (ed.)).

Kementrian Kesehatan RI. (2013b). Riset Kesehatan Dasar (B. P. dan pengembangan Kesehatan (ed.)). Badan Penelitian dan pengembangan Kesehatan.

Lewis \& Parry S. (2013). Premature rupture of the membranes. Journal New Eng J Med, 338(10), 663-669.

McPhee et al. (2012). Patofisiologi Penyakit. EGC.

Mercer et al. (2015). The preterm prediction study premature rupture of the membranes. Journal AmJ Obst-Gynecol, 183, 1-9.

Nugraha G. (2015). Hematologi Dasar. CV. Trans Info Media. 
Prawirohardjo S. (2009). Ilmu Kebidanan. Yayasan Bina Pustaka.

Sudarmi \& Aisyah. (2015). Hubungan infeksi dengan lama persalinan kala II pada Pasien ketuban pecah dini. Journal Media Bina Ilmiah, 9(5).
Widyana E. (2016). Ketuban Pecah Dini dan Kadar Leukosit Pada Ibu Bersalin. Jurnal Kesehatan, 4(3).

World Health Organizaion. (n.d.). Infant mortality. World Health Organization. 